\title{
ANALISIS PENGARUH BERWUDHU TERHADAP PERUBAHAN TEKANAN DARAH SESAAT
}

\author{
Achmad Akbar Ramadhan *), Mochammad Erwin Rachman **) \\ ${ }^{*}$ Mahasiswa Fakultas Kedokteran UMI Makassar \\ ${ }^{* *}$ Staff Dosen Fisiologi Fakultas Kedokteran UMI Makassar \\ Email : m.erwinrachman@yahoo.com.
}

\begin{abstract}
Background : The ablution is a very important Islamic teachings as a condition of validity of prayers, besides ablution provide a very important benefit to human health. Objective: To determine the effect of berwudhu to changes in blood pressure on high school students shortly Global Mandiri Al - Ashri Makassar. Methods: This study used a survey method that uses the analytic approach of Cross Sectional. The samples used were mostly high school students Global Mandiri Al Ashri Makassar as many as 50 people. Results : The results showed a mean systolic blood pressure was $123.56 \mathrm{mmHg}$ before her ablutions, then after berwudhu $122.28 \mathrm{mmHg}$. Mean diastolic blood pressure before berwudhu was $64.08 \mathrm{mmHg}$, and $62.32 \mathrm{mmHg}$ after her ablutions, with kemanaknaan $p>0.005(p=0.270)$. Conclusion: There is a change in blood pressure just before and after her ablutions, although it is not significant .
\end{abstract}

Key words : Ablution, washing the face, the blood pressure momentarily.

\section{PENDAHULUAN}

Islam mengajarkan umatnya untuk menjaga kesehatan dalam hal apapun, baik kesehatan lahir maupun batin. Salah satu contohnya yaitu dengan cara berwudhu. Wudhu merupakan ajaran Islam yang sangat penting dan merupakan syarat sahnya menjalankan sholat. Selain itu, rukunrukun dan sunnah-sunnah wudhu memberikan manfaat yang sangat penting bagi kesehatan tubuh manusia. Namun masih jarang manusia yang mengetahui manfaat wudhu tersebut, serta kurangnya keseriusan dalam melaksanakan rukun-rukun maupun sunnah-sunnah wudhu. Padahal wudhu sangat penting bagi kesehatan tubuh manusia. Contohnya berkumur yang merupakan sunnah wudhu, memiliki manfaat diantaranya dapat menjaga kesehatan mulut, kebersihan gigi, menghilangkan bau mulut, dan sebagainya. Dari contoh ini jelas sekali bahwa Allah SWT menyediakan cara menjaga kesehatan dengan gratis tidak perlu 
membayar mahal, namun sering kita tidak menyadari hal tersebut. $^{1}$

Contoh lain dari beberapa penelitian yang berkaitan tentang faktor-faktor terjadinya kanker kulit telah membuktikan bahwa sebagian besar penyebabnya adalah bersentuhnya kulit dengan materimateri kimia. Oleh sebab itu, cara terbaik untuk mencegah kanker kulit adalah dengan menghilangkan sisasisa bahan kimia tersebut dari permukaan kulit, yaitu dengan cara sering dicuci untuk mengurangi pengaruh materi tersebut terhadap selsel kulit. Sehingga apabila wudhu yang dilakukan secara berulang-ulang setiap hari akan mampu menghilangkan bakteri-bakteri di kulit. Sebagaimana halnya wudhu juga akan menjadikan seorang muslim bersih, disukai, dan diterima oleh lingkungannya. Maka, ketika ia melakukan aktivitas harian, ia memiliki semangat, produktivitas, bahkan optimisme untuk meraih masa depan. ${ }^{2}$

$$
\text { Berdasarkan beberapa }
$$

penelitian sebelumnya yang sebagian besar hanya membahas tentang kesehatan kulit dan pernapasan, sehingga penulis tertarik untuk membuat penelitian tentang manfaat berwudhu terhadap aspek kesehatan lain, yang berjudul "Analisis pengaruh berwudhu terhadap perubahan tekanan darah sesaat pada siswa SMA Global Mandiri Al-Ashri Makassar.

\section{METODOLOGI PENELITIAN}

Jenis penelitian yang dilakukan adalah survei analitik dengan pendekatan cross sectional dengan maksud untuk mempelajari pengaruh berwudhu dan mencuci muka terhadap perubahan tekanan darah pada siswa SMA Global Mandiri Al-Ashri Makassar.

\section{Sampel Penelitian}

Penentuan besar sampel menggunakan rumus Slovin yaitu sebagai berikut: ${ }^{14}$

$$
\begin{aligned}
& \mathrm{n}=\frac{N}{1+N(d)^{2}} \\
& \mathrm{n}=\frac{101}{1+101(0.1)^{2}} \\
& \mathrm{n}=\frac{101}{2,01} \\
& \mathrm{n}=50 \text { orang siswa }
\end{aligned}
$$

Besar sampel yang digunakan yaitu 50 siswa. Dimana :

\section{$\mathrm{n}$ : Besar sampel}

$\mathrm{N}$ : Besar populasi siswa di SMA Global Mandiri Al - Ashri Makassar (101 orang )

d : Tingkat kepercayaan (0.05)

Teknik pengambilan sampel yang digunakan adalah dengan cara Accidental sampling atau convenience sampling artinya cara pengambilan sampel yang dipilih tidak direncanakan 
terlebih dahulu, melainkan secara kebetulan, yaitu unit atau subjek tersedia bagi peneliti saat pengumpulan data dilakukan. ${ }^{14}$

\section{Kriteria inklusi}

a. Siswa SMA Global Mandiri AlAshri Makassar

b. Bersedia untuk dijadikan sampel dalam penelitian

\section{Kriteria Eksklusi}

a. Tidak bersedia untuk dijadikan sampel

\section{Definisi Operasional dan Kriteria Objektif}

1. Berwudhu adalah menggunakan air pada anggota badan tertentu dengan cara tertentu yang dimulai dengan niat guna menghilangkan hadast kecil.

2. Cuci muka adalah membasuh wajah dengan air bersih.

3. Tekanan Darah yaitu tekanan di dalam pembuluh darah ketika jantung memompakan keseluruh tubuh.

Alat Ukur : Data primer

Cara Ukur : Menggunakan sphygmomanometer

\section{Jenis Data}

Jenis data yang dikumpulkan adalah data primer yang diperoleh dari instrumen observasi penelitian yang berupa pengukuran yang diukur dengan sphygmomanometer.
Instrumen penelitian

Adapun instrument yang digunakan adalah observasi dengan bantuan alat ukur berupa sphygmomanometer agar peneliti dapat menilai adanya perubahan tekanan darah sesaat pada siswa SMA Global Mandiri Al-Ashri Makassar.

\section{Manajemen Data}

Pengumpulan data dilakukan secara observasi sistematis, lalu diedit, diolah dan analisis dengan memakai program Microsoft Excel dan SPSS 18. Data yang telah diolah, disajikan dalam bentuk tabel dan grafik kemudian dijelaskan dalam bentuk narasi (uraian) untuk memperjelas hubungan antara variabel dependen dan variabel independen.

\section{HASIL PENELITIAN}

Penelitian ini dilakukan di SMA Global Mandiri Al-Ashri Makassar yang dilaksanakan pada tanggal 16 November 2013. Jumlah sampel dalm penelitian sebanyak 50 orang siswa. Tujuan penelitian ini adalah untuk mengetahui tekanan darah siswa sebelum dan sesudah berwudhu. Alat yang digunakan untuk mengukur tekanan darah siswa adalah sphygmomanometer. Pengukuran tekanan darah dilakukan sebelum berwudhu dan setelah berwudhu. 
Distribusi Variabel Penelitian

Variabel dalam penelitian

adalah tekanan darah sistole dan dan sesudah dilakukan eksperimen berupa berwudhu maupun mencucii muka. diastole siswa yang diperiksa sebelum

Tabel 5.1. Distribusi responden menurut tekanan darah sebelum berwudhu siswa SMA Global Mandiri Al-Ashri Makassar Tahun 2013

\begin{tabular}{lcc}
\hline Tekanan Darah Awal Sebelum Berwudhu & N & $\%$ \\
\hline Normal & 42 & 84,0 \\
Hipertensi & 8 & 16,0 \\
\hline Total & $\mathbf{5 0}$ & $\mathbf{1 0 0}$ \\
\hline
\end{tabular}

Sumber : Data Primer

Tabel 5.1 menunjukkan bahwa

sebelum berwudhu umumnya responden mempunyai tekanan darah normal yaitu 42 siswa $(84,0 \%)$.

Semua responden mempunyai tekanan darah awal sebelum mencuci muka adalah normal yaitu 50 siswa $(100,0 \%)$
Tekanan darah akhir

Distribusi

responden dan diastole sebelum berwudhu dapat dilihat pada tabel berikut:

Perbedaan tekanan darah sistole sebelum dan sesudah berwudhu

Perbedaan tekanan darah sistole sebelum dan setelah berwudhu dapat dilihat pada tabel berikut:

Tabel 5.2. Perbedaan Tekanan Darah Sistole Sebelum dan Sesudah Berwudhu Siswa SMA Global Mandiri Al-Ashri Makassar Tahun 2013

\begin{tabular}{lccc}
\hline \multicolumn{1}{c}{ Tekanan Darah Sistole } & Mean & SD & p \\
\hline Sebelum Wudhu & 123,56 & 13,974 & \multirow{2}{*}{0,270} \\
\hline Setelah Wudhu & 122,28 & 16,296 & \\
\hline
\end{tabular}

Sumber : Data Primer

Tabel 5.2 menunjukkan bahwa rerata tekanan darah sistole sebelum berwudhu adalah 123,56 $\mathrm{mmHg}$ dan sesudah berwudhu menurun menjadi 122,28 mmHg. Hasil uji statistik dengan uji $\mathrm{t}$ berpasangan (paired sampel test ) diperoleh nilai $p=0.270$ $(p>0,05)$ yang berarti Ho diterima. Hal ini menunjukkan bahwa tidak ada pengaruh berwudhu terhadap tekanan darah sistole siswa karena tekanan darah sistole siswa sama.

Perbedaan tekanan darah diastole sebelum dan sesudah berwudhu

Perbedaan tekanan darah diastole sebelum dan setelah berwudhu dapat dilihat pada tabel berikut: 
Tabel 5.3. Perbedaan Tekanan Darah Diastole Sebelum dan Sesudah Berwudhu Siswa SMA Global Mandiri Al-Ashri Makassar Tahun 2013

\begin{tabular}{|l|c|c|c|}
\hline \multicolumn{1}{|c|}{ Tekanan Darah Diastole } & Mean & SD & p \\
\hline Sebelum Wudhu & 64,08 & 9,16 & \multirow{2}{*}{0,059} \\
\hline Setelah Wudhu & 62,32 & 10,32 & \\
\hline
\end{tabular}

Sumber : Data Primer

Tabel 5.3 menunjukkan bahwa rata rata tekanan darah diastole sebelum berwudhu adalah $64,08 \mathrm{mmHg}$ dan sesudah berwudhu menurun menjadi 62,32 mmHg. Hasil uji statistik dengan uji $t$ berpasangan (paired sampel test ) diperoleh nilai $p=0.059$ ( $p>0,05)$ yang berarti Ho diterima. Hal ini menunjukkan bahwa tidak ada pengaruh berwudhu terhadap tekanan darah diastole siswa.

\section{PEMBAHASAN}

\section{Pengaruh berwudhu terhadap tekanan darah}

Hasil penelitian menunjukkan bahwa rata -rata tekanan darah sistolik maupun diastolik siswa mengalami penurunan setelah berwudhu. Namun hasil uji paired sampel t-test, menunjukkan bahwa tidak ada pengaruh berwudhu terhadap penurunan tekanan darah sistole dan diastole siswa. Hal ini menunjukkan bahwa berwudhu dapat menurunkan tekanan darah siswa walau penurunan itu tidak signifikan. Secara umum sebelum berwudhu umumnya siswa mempunyai tekanan darah normal yaitu $84,0 \%$, setelah berwudhu semua siswa mempunyai tekanan darah normal (100\%).

Wudhu bukan hanya menjadi syarat sahnya menjalankan sholat, namun juga merupakan ajaran Islam yang mengajarkan tentang perlunya kebersihan secara lahiriah maupun bathiniah dalam menjalankan ibadah. Wudhu yang dijalankan dengan penuh kesungguhan, khusyu', tepat, ikhlas dan kontinu, dapat menumbuhkan persepsi dan motivasi positif serta mengefektifkan coping. Respon emosi positif (positive thinking), dapat menghindarkan reaksi stres. ${ }^{1}$

Manfaat Wudhu bagi kesehatan tubuh manusia, Wudhu memiliki makna yang luar biasa hebatnya baik untuk kesehatan fisik, mental bahkan keseimbangan spiritual dan emosional. Manfaat wudhu bagi kesehatan tubuh manusia yaitu menjaga tubuh dari penyakit mulut, tangan dan kaki, menjamin kebersihan kedua mata, menjaga keselamatannya serta menghindari penyakit trahum dan radang mata, mencegah timbulnya jerawat, mampu mengurangi tekanan darah tinggi atau hipertensi dan pusing 
kepala, dan memperkuat peredaran darah sehingga dapat menambah aktivitas dan kebugaran tubuh. ${ }^{1}$

Wudhu dapat menstabilkan tekanan darah, menambah gerakan jantung, menambah jumlah sel-sel darah merah, mengaktifkan pertukaran (sirkulasi) dalam tubuh, menambah kadar oksigen, serta memperbanyak kadar $\mathrm{CO}_{2}$ (Carbon dioksida) yang keluar, serta masih banyak manfaat lainnya. ${ }^{5}$

Wudhu dapat menstimulasi atau merangsang irama tubuh secara alami. Pada tubuh terdapat area yang disebut Biological Active Spots atau BASes alias titik aktif Biologi. BASes memiliki kemiripan dengan titik-titik refleksi ala Cina. BASes pada tubuh berjumlah sekitar 700, dan 65 diantaranya memiliki efek refleksi cepat yaitu hanya dengan usapan saja bisa aktif. Sementara sisanya harus dipijat atau ditusuk dengan jarum untuk mengaktifakannya. Magomedov juga menyatakan bahwa 61 dari 65 titik tadi merupakan bagian-bagian yang dibasuh ketika wudhu. Dengan demikian sebenarnya pada saat kita berwudhu kita telah melakukan hidromassage yaitu pemijatan menggunakan media air. Selain itu dengan berwudhu kita juga melancarkan metabolisme tubuh kita.
Karena ujung jutaan syaraf yang berhubungan dengan sistem Metabolisme tersebar di sepanjang permukaan kulit. Contoh saat membasuh muka pijatan akan memberikan efek positif pada usus, ginjal dan system saraf maupun reproduksi. Membasuh telinga akan merangsang penurunan tekanan darah, mengurangi rasa sakit dan meningkatkan kekhusu'uan ketika Sholat. ${ }^{15}$

Manfaat mengusap sebagian kepala pada saat berwudhu adalah mampu mengurangi tekanan darah tinggi atau hipertensi dan pusing kepala. Sebab air dingin yang dibasuh ke wajah ataupun diusapkan ke kepala akan memiliki pengaruh yang baik untuk aktivitas dan kebugaran seseorang, dan dapat menghilangkan penyakit kepala serta kelelahan otak. Ketika menyapu kepala, rambut menjadi lebih bersih dan terasa segar. Selain itu rambut menjadi rapi dan enak dipandang. ${ }^{5}$

Peredaran darah pada ujung kedua telapak tangan serta ujung kedua telapak kaki dan betis lebih lemah dibanding peredaran darah pada anggota tubuh lainnya, karena ujung kedua telapak tangan dan lengan serta ujung kedua telapak kaki dan betis adalah anggota tubuh yang 
paling jauh dari pusat peredaran darah yakni jantung. Oleh karena itu, membasuh semua ujung-ujung anggota tubuh yang disebutkan tadi saat berwudhu dan memijatnya dengan baik akan memperkuat peredaran darah sehingga dapat menambah aktivitas dan kebugaran tubuh. ${ }^{1}$

Membasuh kaki akan membuat kaki terasa nyaman dan segar, melemaskan otot-otot kaki yang tegang dan menghilangkan bau kaki yang tidak sedap serta menjadikan kuku bebas dari jamur. ${ }^{1,3}$

Tekanan darah adalah tekanan di dalam pembuluh darah ketika jantung memompakan keseluruh tubuh. Umumnya semakin rendah tekanan darah, semakin sehat anda untuk jangka panjang (kecuali dalam kondisi tertentu ketika tekanan darah sangat rendah merupakan bagian suatu penyakit). ${ }^{6,7}$

Darah mengambil oksigen dari dalam paru-paru. Darah yang mengandung oksigen ini memasuki jantung dan kemudian dipompakan keseluruh bagian tubuh melalui pembuluh darah yang disebut arteri. Pembuluh darah yang lebih besar bercabang-cabang menjadi pembuluhpembuluh darah yang lebih kecil hingga berukuran mikroskopik, yang akhirnya membentuk jaringan yang terdiri dari pembuluh-pembuluh darah yang sangat kecil yang disebut kapiler. Jaringan ini mengalirkan darah ke selsel tubuh dan menghantarkan oksigen untuk menghasilkan energi yang dibutuhkan demi kelangsungan hidup. Kemudian darah yang tidak beroksigen kembali ke jantung melalui pembuluh darah vena, dan dipompa kembali ke paru-paru untuk mengambil oksigen lagi. $^{7}$

Saat jantung berdetak, otot jantung berkontraksi untuk memompakan darah ke seluruh tubuh. Tekanan tertinggi berkontraksi dikenal sebagai tekanan sistolik. Kemudian otot jantung rileks sebelum kontraksi berikutnya, dan tekanan ini paling rendah, yang dikenal sebagai tekanan diastolik. Tekanan sistolik dan diastolik ini diukur ketika Anda memeriksakan tekanan darah. ${ }^{8,9}$

Wudhu efektif mengendalikan emosi. Setiap kali merasa ingin marah, seorang muslim sangat dianjurkan untuk mengambil air wudhu untuk mendinginkan pikiran dan menentramkan hati. Pada saat seseorang marah maka tekanan darah akan meningkat sehingga kerja jantung akan lebih besar untuk memompa darah. Orang yang marah akan kelihatan merah mukanya karena 
darah banyak berkumpul di muka orang tersebut. Dengan berwudhu akan mendinginkan muka serta saraf saraf sehingga akan menurunkan tekanan darahnya. Apa pun yang telah diperintahkan oleh Allah tentu memberi banyak manfaat dan solusi tanpa meninggalkan resiko. Oleh karenanya, mari sebagai seorang muslim kita budayakan kebiasaan untuk selalu berwudhu dalam keseharian kita .Allah sangat mencintai orang-orang yang selalu membersihkan diri. ${ }^{16}$

Wudhu juga bisa memperlancar aliran darah. Ketika air wudhu membasuh anggota wudhu, secara langsung akan membuat darah bereaksi sehinga bekerja bisa lebih cepat mengalirkan darah keseluruh tubuh. Hal ini bisa terjadi karena air wudhu mengenai tubuh akan menyebabkan normalisasi suhu tubuh sebagai akibat bertemunya suhu panas dalam tubuh dengan dinginnya guyuran air wudhu. Saat itu juga darah mengalir kedaerah seputar wajah, kedua tangan dan telapak kaki dengan sangat lancar. Lancarnya aliran darah pada seluruh tubuh akan membuat kelenjar kulit bekerja. Tugas kelenjar kulit ini adalah menyedot darah-darah kotor dan membuangnya keluar tubuh melalui pembuluh-pembuluh halus yang terletak dipermukaan kulit. Maka begitu darah kotor itu keluar, air wudhu akan langsung membersihkannya. Efek dari proses ini adalah kulit di sekitar wajah dan bagian tubuh yang lain akan selalu tampak segar dan berseri-seri. ${ }^{17}$

Untuk kesehatan jantung. Tugas jantung adalah memompa darah keseluruh bagian tubuh. Semakin jauh dari bagian yang akan dipompa maka kerja jantung akan semakin besar. Daerah-daerah yang jauh itu antara lain wajah, telapak tangan dan kaki, ketika berwudhu maka jantung akan langsung bereaksi dan kemudian memompa darah dengan kuat menuju tiga anggota badan yang berjauhan itu, sehingga beban kerja jantung semakin berkurang. ${ }^{17}$

Hal ini akan mencegah terjadinya serangan jantung. Berwudhu ternyata membantu mengurangi beban berat kerja ginjal dan dampaknya bisa meminimalisir kemungkinan terkena resiko sakit ginjal. Ginjal merupakan organ tubuh yang bertugas membuang zat-zat baracun, ketika tugas ini telah dibantu oleh pembuluh darah yang ada dipermukaan kulit maka tugas ginjal juga akan berkurang. ${ }^{17}$ 


\section{KESIMPULAN}

Berdasarkan hasil penelitian yang kami lakukan mengenai analisis pengaruh berwudhu terhadap perubahan tekanan darah sesaat pada siswa SMA Global Mandiri Al-Ashri Makassar pada bulan Oktober 2013, maka dapat ditarik kesimpulan sebagai berikut :

1. Rerata tekanan darah sistole sebelum berwudhu adalah 123,56 $\mathrm{mmHg}$ dan sesudah berwudhu menurun menjadi $122,28 \mathrm{mmHg}$. Rata-rata tekanan darah diastole sebelum berwudhu adalah 64,08 $\mathrm{mmHg}$ dan sesudah berwudhu menurun menjadi $62,32 \mathrm{mmHg}$

2. Ada pengaruh berwudhu terhadap tekanan darah sistole maupun diastole siswa. Tekanan darah sistole maupun diastole siswa cenderung menurun setelah berwudhu walaupun penurunan tersebut tidak signifikan.

\section{DAFTAR PUSTAKA}

1. Musbikin Imam. Wudhu Sebagai Terapi. Yogyakarta: Nusa media: 2008.

2. Ahmad bin Salim Baduwailan, AtTadawi bi As-Shalah, diterjemahkan oleh Widyan Wahyudi, Terapi Mengobati Penyakit Dengan Shalat. Pustaka at-Tazkia, Jakarta, 2008.
3. Guyton, Hall. Tekanan Darah. Dalam: Buku Ajar Fisiologi Kedokteran Edisi 9. Jakarta: EGC: 1997. hal.134-215.

4. Sylvia Anderson. Konsep Klinik proses-proses Penyakit. Dalam: Patofisiologi Bagian 1, Edisi 2. Editor: Adji Dharma. Jakarta: EGC: 1991. hal. 384-390.

5. Budhi Setianto. Fisiologi Jantung dan Pembuluh darah. Dalam: Buku Ajar Kardiologi. Jakarta: FK.UI: 1996. hal. 15-18.

6. Bambang.Struktur Jantung. Dalam: Kamus Saku Kedokteran Dorland Edisi 29. Editor: Hurniawati Hartanto, dkk. Jakarta: EGC: 2002. hal. 1151.

7. Soehardo Kertohoesodo. Peredaran Darah. Dalam: Sistem Kardiovaskuler. Jakarta: Pradnya paramita: 1988. hal. 9-30.

8. Guyton. Vaskuler. Dalam: Fisiologi Manusia. Editor: Petrus Andrianto. Penerbit: EGC. Hal. 161-169.

9. Rushmer, R.F., Cardiovascular dynamics. Philadelphia: W.B. Saunders Company, 1981. hal. 155-91.

10. Sauqi Alif Zaelani, Sistem Sirkulasi Darah dalam Tubuh Manusia. Dalam: Biologi. Jakarta: EMD: 2006.hal. 54.

11. Magomedov. Muslims Rituals and Their Effect on the Person's Health. Dalam: Muslim and Health. Jakarta: Syifaila :2009.hal. 5-17. 